\title{
Psychometric Properties of The Turkish Version of HEDEN Pain Scale in Pediatric Patients with Cancer: Preliminary Results
}

Atiye KARAKUL*,Esra ARDAHAN AKGÜL*, Nuray DEMİ***, Beste ÖZGÜVEN ÖZTORNACI*, PInar DOĞAN*, Medine YILMAZ***, Hatice YILDIRIM SARI*

*İzmir Katip Çelebi University, Faculty of Health Sciences, Department of Pediatric Nursing

** Ege University Tülay Aktaş Oncology Hospital, Pediatric Oncology Department

*** İzmir Katip Çelebi University, Faculty of Health Sciences, Department of Public Health Nursing

\section{INTRODUCTION}

Chronic pain is very common among pediatric patients with cancer. The evaluation of physiological parameters (heart rate, oxygen saturation, blood pressure, salivation) in chronic pain may not always be possible. Long-term cancer pain in children is reported to have complex consequences such as increased irritability, low mood, difficulty in sleep, hostility, loss of appetite, and drop in school performance. When the researches are examined, it is seen that there are many tools used in the diagnosis of acute pain and interventional pain, however it is seen that valid reliable measurement tools that can be used for long-term and chronic pain measurement are limited.

This study aimed to examined the psychometric properties of the Turkish version of HEDEN Pain Scale.

\section{METHODS}

The study was conducted with children aged 2 to 6 years in the Pediatric Oncology Department. Inclusion criteria;

$>$ The child lies in the oncology ward

> Between 2-6 years of age (age limitation of sample was made because the scale used in the study was suitable for children aged 2-6 years)

$>$ The family accepts to participate in the research

$>$ Pain lasting more than 24 hours

$>$ Lack of psychosocial discomfort

$>$ Verbal communication

Intruments

$>$ The Sociodemographic Characteristics Questionnaire

$>$ HEDEN Pain Scale

$>$ FLACC Behavioral Pain Evaluation Scale

Language equivalence and content validity were assessed by ten experts. Reliability of parallel forms method, Cronbach alpha, validity of language and scope in validity analysis, KMO-Barlett test, principal component analysis, varimax rotation, Hotelling $t$ test methods were used for analysis of reliability and validity.

\section{RESULTS}

In the study, 50 pain evaluations were made in 35 children. The children's mean age $4.45 \pm 1.4,65.7 \%$ (n: 23 ) were girls and $34.3 \%$ (n:12) were boys. KGI was 0.90 based on the Davis technique. KMO value was $0.68, p=0.000$, Chi-Square $=38.581$, and the factor analysis showed that the scale was onedimensional.

Table 1.Sociodemographic Characteristics of Childrens

\begin{tabular}{|l|l|l|}
\hline \multicolumn{2}{|l|}{ Number (N) } & Percentage (\%) \\
\hline Gender & 23 & 65.7 \\
\hline Girls & 12 & 34.3 \\
\hline Boys & \multicolumn{2}{l|}{} \\
\hline Diagnosis & 14 & 28 \\
\hline ALL & 13 & 26 \\
\hline Sarcoma & 9 & 18 \\
\hline Medulloblastoma & 10 & 20 \\
\hline Neuroblastoma & 4 & 8 \\
\hline Astrocytoma & \multicolumn{2}{|l|}{} \\
\hline Cause of pain & 16 & 32 \\
\hline Treatment associated & 32 & 64 \\
\hline Disease associated & 2 & 4 \\
\hline Treatment and disease & & \\
\hline associated & & \\
\hline Pain area * & & 44.24 \\
\hline Abdominal / pelvic region & 23 & 13.46 \\
\hline Lower extremity & 7 & 42.30 \\
\hline Upper extremity & 22 & 24 \\
\hline Analgesic & & \\
\hline Yes & 38 & \\
\hline No & 12 & \\
\hline
\end{tabular}

* There has been recurrence because the pain area is more than one

The reliability of the parallel forms $\mathrm{r}=0.86 \mathrm{p}=0.000$. The Cronbach alpha value is 0.72 . It was determined that children perceived scale items in the same way (Hotelling t test $37.42, \mathrm{p}=0.000$ ). The mean score of the scale was $5.3 \pm 2.2(1-10)$

\section{CONCLUSIONS}

The research findings show that the HEDEN scale is valid and reliable for chronic pain assessment in children with cancer. Also this scale is a faster and easier to use pain assessment tool.

\section{REFERENCES}

Carter BD, Threlkeld BM. Psychosocial perspectives in the treatment of pediatric chronic pain. Pediatric Rheumatology 2012;10:15

Cohen LL, Lemanek K, Blount RL, Dahlquist LM, Lim CS, Palermo TM, McKenna KD, Weiss KE. Evidence-based assessment of pediatric pain J Pediatr Psychol 2008:3:939-955.

Huguet A, Miro J. The severity of chronic pediatric pain: an epidemiological study. J Pain 2008:9:3:226-236.

King S, Chambers CT, Huguet A, MacNevin RC, McGrath PJ, Parker L, et al. The epidemiology of chronic pain in children and adolescents revisited: A systematic review. Pain 2011:152:2: 2729-2738.

Malviya S, Voepel-Lewis T, Burke C, Merkel S, Tait AR. The revised FLACC observational pain tool: improved reliability and validity for pain assessment in children with cognitive impairment. Paediatr Anaesth. 2006;16:258-265.

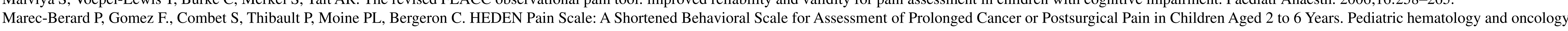
2015; 32:5:291-30.

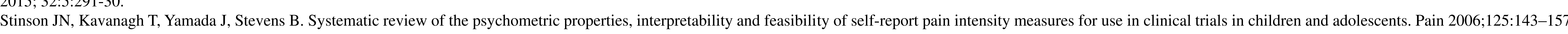

